\title{
Treatment Effect or Secret Nature: Long-Term Remissions in Metastatic Pancreatic Cancer
}

\author{
Markus Horneber \\ Department of Internal Medicine, Division of Oncology/Hematology, Klinikum Nuremberg, Germany
}

Pancreatic carcinoma is one of the most lethal solid malignancies and the fourth to fifth leading cause of cancer-related deaths in Germany, where nearly 14,000 cases are diagnosed annually, with a similar number of patients dying from the disease. It is seen equally in men and women, median age at diagnosis for men is 69 and for women 76 years and less than $3 \%$ are diagnosed under the age of 45 [1]. More than half of all patients present with disease extending beyond the pancreas and regional lymph nodes with metastases to the liver or other organs. Without treatment, these patients survive no longer than 2-3 months. Since the late nineties, gemcitabine has become the standard first-line palliative treatment. However, survival remained modest with median survival times of 6 months and 1-year survival rates of less than $20 \%$. Over the last years, large efforts have been made to improve treatment outcomes in metastatic pancreatic cancer with mainly disappointing results. Pooled data from randomized trials provided some evidence that in patients with good performance status, survival was improved when gemcitabine was combined, especially with platinum-based agents [2, 3].

In this issue, Ritter et al. [4] report on a 43-year-old woman with metastatic pancreatic adenocarcinoma who experienced a long-term remission. The patient underwent resection of the pancreatic head, regional lymph nodes, and a single liver segment. After 9 months of treatment with gemcitabine and oxaliplatin and a continued application of mistletoe extracts, the patient is alive and in good condition without evidence of tumor progression 12 months after finishing first line chemotherapy. Quite rightly, for everyone immersed in the daily effort of caring for sufferers with pancreatic cancer, this case report is satisfying and the authors' conclusion that 'cases of sustained long-term remission of metastatic pancreatic cancer are extremely rare' underlines the common experience.

From an analytical point of view the question arises whether this case is a rare exception or represents a small group of long-term responders. Looking into the literature an answer to this question is difficult to find. Only 3 studies with patients with metastatic disease treated with gemcitabine and/or oxaliplatin published follow-up data extending up to 2 years. However, progression-free survival rates could only be estimated by reading them directly from the Kaplan-Meier curves and it appears to be a tiny 1-2\% [5-7]. Applying these figures to a hypothetical group of women who were diagnosed with metastatic pancreatic cancer in Germany within one year and treated with gemcitabine or a gemcitabine-based combination $(\sim 3,000), 30-60$ of those would have been still alive and with no evidence of recurrence 2 years later. Based on these (admittedly small) figures most colleagues involved in the care of cancer patients should have had comparable encounters as the authors of the case report.

In an attempt to assess the predictors of prolonged survival, Goulart et al. [8] retrospectively analyzed the outcome of patients diagnosed with adenocarcinoma of the pancreas with metastatic or recurrent disease who had received singleagent gemcitabine and survived more than one year. Among the whole group of 435 unselected patients, the authors found 20 subjects matching these criteria. Those $5 \%$ of survivors had a median overall survival (OS) of 27 months and a 2-year OS rate of $56 \% .5$ patients $(25 \%)$ had an objective radiological response to gemcitabine and their median OS was 5 months higher, compared to that for non-responders. However, the statistical analysis revealed that neither treatment-related factors nor clinical characteristics predicted the survival within this small group. Only bilirubin and CA19-9 at baseline were inversely and significantly associated with OS. These latter findings notwithstanding, the data of this retrospective analysis gave at least a subtle hint that an increased responsiveness to gemcitabine might have accounted for the prolonged remission and survival in the 43-year-old woman reported here.

The authors of the case report published in this issue, however, assumed that chemotherapy (and surgery) was less likely to be the 'major reason' for the stable long-term remission but rather the treatment with mistletoe extracts. As of yet there is no evidence from clinical trials in support of mistletoe extracts

\section{KARGER}

Fax +497614520714

Information@Karger.de

www.karger.com
(C) 2010 S. Karger GmbH, Freiburg

Accessible online at:

www.karger.com/onk 
having impact on tumor remission or survival of patients with metastatic pancreatic cancer: i) In a prospective uncontrolled trial, 16 patients with stage III or IV received a lectin-standardized mistletoe extract twice weekly as sole treatment. No tumor remissions were seen and median OS was 3,5 months in stage IV patients [9]. ii) In a retrospective cohort study, 201 patients with stage I-IV pancreatic cancer treated with chemotherapy and a mistletoe extract were compared with 195 patients treated with chemotherapy alone. The hazard ratio for OS in stage IV patients was below 1 but the confidence interval overlapped (HR 0,65; 95\% CI 0,35-1,20) and the study was at high risk for selection bias [10]. iii) In a phase I trial, 10 pancreatic cancer patients, among 44 other patients with advanced solid tumors, received escalating doses of gemcitabine and mistletoe extracts, and 2 of them experienced a partial response [11].

In the end, the question arises whether neither of the treatment measures alone but rather the combination of surgery, chemotherapy and mistletoe extracts might have influenced the favorable course of the 43-year-old woman. In a recent study, 16 pancreatic cancer patients, the majority with advanced or metastatic disease, were comprehensively immunomonitored before and after surgery and chemotherapy [12]. The authors found that, after surgery and chemotherapy, the secretion of Th1 type cytokines, the allostimulatory capacity of dendritic cells, and NK/LAK cytotoxicity were increased. Furthermore, a decrease of IL-10 production was seen after chemotherapy. The authors concluded that their findings suggested that it may in future be possible to rationally combine immunotherapy with these therapeutic modalities, capitalizing on an additive or even a synergistic activity.' Taken these preliminary data together with the findings that mistletoe extracts are capable of inducing TNF-alpha and IL12, of stimulating a specific Th1 response, of mediating antitumor T-cell responses and of reducing the secretion of IL-10 in humans [13], one might speculate that effects on the immune system such as these and the above mentioned ones, could have occurred in the 43-year-old woman reported here and contributed to the long-term remission of her disease. However, the small empirical basis of this assumption brings to mind the current lack of knowledge about markers that might be capable of reliably predicting prognosis and treatment response in pancreatic cancer patients.

Richard C. Frank, a medical oncologist from Norwalk, USA, recently described a situation in which he was faced with a sustained remission in a 60 -year-old patient with metastatic pancreatic cancer, 18 months after starting chemotherapy: 'I recently saw Bruce in my office, a year and a half after our initial conversation. He comes for weekly chemotherapy treatments, works full time, has traveled abroad, and looks fit. Is he cured? No. How long will he live? I don't know. How did this happen? I cannot say' [14].

\section{References}

1 Husmann G, Kaatsch P, Katalinic K, Bertz J, Haberland J, Kraywinkel K, Wolf U: Krebs in Deutschland 2005/2006 - Häufigkeiten und Trends; Berlin, Robert Koch Institut, 2010, pp 1-121.

2 Heinemann V, Boeck S, Hinke A, Labianca R, Louvet C: Meta-analysis of randomized trials: evaluation of benefit from gemcitabine-based combination chemotherapy applied in advanced pancreatic cancer. BMC Cancer 2008;8:82.

$\checkmark 3$ Sultana A, Smith CT, Cunningham D, Starling N, Neoptolemos JP, Ghaneh P: Meta-analyses of chemotherapy for locally advanced and metastatic pancreatic cancer. J Clin Oncol 2007;25:2607-2615.

4 Ritter PR, Tischoff I, Uhl W, Schmidt WE, Meier JJ: Sustained partial remission of metastatic pancreatic cancer following systemic chemotherapy with gemcitabine and oxaliplatin plus adjunctive treatment with mistletoe extract. Onkologie 2010 33:617-619.

5 Louvet C, Labianca R, Hammel P, Lledo G, Zampino MG, Andre T, Zaniboni A, Ducreux M, Aitini E, Taieb J, Faroux R, Lepere C, de Gramont A; GERCOR; GISCAD: Gemcitabine in combination with oxaliplatin compared with gemcitabine alone in locally advanced or metastatic pancreatic cancer: results of a GERCOR and GISCAD phase III trial. J Clin Oncol 2005;23:3509-3516.
6 Poplin E, Feng Y, Berlin J, Rothenberg ML, Hochster H, Mitchell E, Alberts S, O`Dwyer P, Haller D, Catalano P, Cella D, Benson AB, III: Phase III, randomized study of gemcitabine and oxaliplatin versus gemcitabine (fixed-dose rate infusion) compared with gemcitabine (30-minute infusion) in patients with pancreatic carcinoma E6201: a trial of the Eastern Cooperative Oncology Group. J Clin Oncol 2009;27:3778-3785.

7 Alberts SR, Townley PM, Goldberg RM, Cha SS, Sargent DJ, Moore DF, Krook JE, Pitot HC, Fitch TR, Wiesenfeld M, Mailliard JA: Gemcitabine and oxaliplatin for metastatic pancreatic adenocarcinoma: a North Central Cancer Treatment Group phase II study. Ann Oncol 2003;14: 580-585.

8 Goulart BH, Clark JW, Lauwers GY, Ryan DP, Grenon N, Muzikansky A, Zhu AX: Long term survivors with metastatic pancreatic adenocarcinoma treated with gemcitabine: a retrospective analysis. J Hematol Oncol 2009;2:13.

-9 Friess H, Beger HG, Kunz J, Funk N, Schilling M, Büchler MW: Treatment of advanced pancreatic cancer with mistletoe: results of a pilot trial. Anticancer Res 1996;16:915-920.

10 Matthes H, Friedel WE, Bock PR, Zanker KS: Molecular mistletoe therapy: friend or foe in established anti-tumor protocols? A multicenter, controlled, retrospective pharmaco-epidemiological study in pancreas cancer. Curr Mol Med 2010;10: 430-439.
11 Mansky PJ, Wallerstedt DB, Sannes T, Stagl L, Johnson MR, Blackman MR, Grem JL, Swain SM, Monahan BP: NCCAM/NCI phase I study of mistletoe extract and gemcitabine in patients with advanced solid tumors; J Clin Oncol 2010;28: 15S:2559.

12 Bellone G, Novarino A, Vizio B, Brondino G, Addeo A, Prati A, Giacobino A, Campra D, Fronda GR, Ciuffreda L: Impact of surgery and chemotherapy on cellular immunity in pancreatic carcinoma patients in view of an integration of standard cancer treatment with immunotherapy. Int J Oncol 2009;34:1701-1715.

13 Heinzerling L, von Baehr V, Liebenthal C, von Baehr R, Volk HD: Immunologic effector mechanisms of a standardized mistletoe extract on the function of human monocytes and lymphocytes in vitro, ex vivo, and in vivo. J Clin Immunol 2006; 26:347-359.

14 Frank RC: The hardest job in medicine. J Clin Oncol 2010;28:181. 